\title{
Palmitoylethanolamide in the Treatment of Failed Back Surgery Syndrome
}

\author{
Antonella Paladini, ${ }^{1}$ Giustino Varrassi, ${ }^{2}$ Giuseppe Bentivegna, ${ }^{3}$ Sandro Carletti, ${ }^{4}$ \\ Alba Piroli, ${ }^{1}$ and Stefano Coaccioli ${ }^{2,3}$ \\ ${ }^{1}$ Department of MESVA, School of Medicine, University of L’Aquila, L’Aquila, Italy \\ ${ }^{2}$ Paolo Procacci Foundation, Rome, Italy \\ ${ }^{3}$ Department of Internal Medicine, Rheumatology and Medical Pain Therapy, Perugia University School of Medicine, Terni, Italy \\ ${ }^{4}$ Department of Neurosurgery, "Santa Maria" General Hospital, Terni, Italy
}

Correspondence should be addressed to Giustino Varrassi; giuvarr@gmail.com

Received 1 February 2017; Revised 7 April 2017; Accepted 16 May 2017; Published 10 August 2017

Academic Editor: Donald A. Simone

Copyright (C) 2017 Antonella Paladini et al. This is an open access article distributed under the Creative Commons Attribution License, which permits unrestricted use, distribution, and reproduction in any medium, provided the original work is properly cited.

\begin{abstract}
Introduction. This observational study was designed to evaluate the efficacy of ultramicronized palmitoylethanolamide (um-PEA) (Normast ${ }^{\circledR}$ ) administration, as add-on therapy for chronic pain, in the management of pain-resistant patients affected by failed back surgery syndrome. Methods. A total of 35 patients were treated with tapentadol (TPD) and pregabalin (PGB). One month after the start of standard treatment, um-PEA was added for the next two months. Pain was evaluated by the Visual Analogue Scale (VAS) at the time of enrollment $\left(T_{0}\right)$ and after one $\left(T_{1}\right)$, two $\left(T_{2}\right)$, and three $\left(T_{3}\right)$ months. Results. After the first month with TDP + PGB treatment only, VAS score decreased significantly from $5.7 \pm 0.12$ at the time of enrollment $\left(T_{0}\right)$ to $4.3 \pm 0.11\left(T_{1}\right)$ $(p<0.0001)$; however, it failed to provide significant subjective improvement in pain symptoms. Addition of um-PEA led to a further and significant decrease in pain intensity, reaching VAS scores of $2.7 \pm 0.09\left(T_{2}\right)$ and $1.7 \pm 0.11\left(T_{3}\right.$, end of treatment) $(p<0.0001)$ without showing any side effects. Conclusions. This observational study provides evidence, albeit preliminary, for the efficacy and safety of um-PEA (Normast) as part of a multimodal therapeutic regimen in the treatment of pain-resistant patients suffering from failed back surgery syndrome.
\end{abstract}

\section{Introduction}

Failed back surgery syndrome (FBSS) can be defined as "surgical end stage after one or several operative interventions on the lumbar neuroaxis, indicated to relieve lower back pain, radicular pain, or the combination of both without positive effect" [1]. Clinical presentation is characterized as a chronic pain syndrome which severely impacts the quality of a patient's professional and personal life. Typically, symptoms associated with FBSS include diffuse, dull, and aching pain, sharp, pricking pain involving the back and legs, and stabbing pain in the extremities due to abnormal sensibility. Several factors can contribute to the onset or development of FBSS including, but not limited to, either residual or recurrent disc herniation, persistent postoperative nerve root pressure, altered joint mobility, axial hypermobility with instability, scar tissue and fibrosis, depression, anxiety, and spinal muscular pain. An individual's predisposition to the development of FBSS might be due to systemic disorders such as diabetes, autoimmune disease, and peripheral vascular disease $[2,3]$. Although the etiology, underlying mechanisms, and pathoanatomic correlations can differ greatly across cases of FBSS, there is a consensus that this syndrome is typically "mixed," inasmuch as there are both nociceptive and neuropathic mechanisms responsible for pain $[2,4]$. Treatment of FBSS includes a wide range of therapeutic options such as pharmacologic agents, physical therapy, behavioral medicine, transcutaneous electrical nerve stimulation, minor nerve blocks, and pulsed electromagnetic therapy [5]. The objectives of management should be directed to restoration of functional ability, improvement of quality of life, coping strategies, and pain self-management $[2,6]$. A stereotyped 
TABle 1: Patients' demographic and medical information.

\begin{tabular}{|c|c|c|c|}
\hline & All & Male & Female \\
\hline Number of patients, $n(\%)$ & 35 & $15(42.9)$ & $20(67.1)$ \\
\hline Mean age $\pm S D$ & $51.9 \pm 14.7$ & $49.3 \pm 15.6$ & $53.8 \pm 14.1$ \\
\hline \multicolumn{4}{|l|}{ Surgical interventions, $n(\%)$} \\
\hline Laminectomy & $5(14.3)$ & $3(20.0)$ & $2(10.0)$ \\
\hline Discectomy & $24(68.6)$ & $12(80.0)$ & $12(60.0)$ \\
\hline Vertebral stabilization & $6(17.1)$ & 0 & $6(30.0)$ \\
\hline \multicolumn{4}{|l|}{ Comorbidities $^{*}, n(\%)$} \\
\hline Hypertension & $12(34.3)$ & $5(33.3)$ & $7(35.0)$ \\
\hline Obesity & $10(28.6)$ & $3(20.0)$ & $7(35.0)$ \\
\hline Osteoarthritis & $10(28.6)$ & $5(33.3)$ & $5(25.0)$ \\
\hline Chronic obstructive pulmonary disease & $3(8.6)$ & 0 & $3(15.0)$ \\
\hline Chronic ischemic cardiomyopathy & $2(5.7)$ & $1(6.7)$ & $1(5.0)$ \\
\hline None & $9(25.7)$ & $5(33.3)$ & $4(20.0)$ \\
\hline
\end{tabular}

${ }^{*}$ Total is not $35(100 \%)$ because some patients may present more comorbidities.

approach is unlikely to succeed since each patient deserves individual consideration for management [2]. Therefore, it is important for physicians who treat this population to expand their knowledge of FBSS etiologies with appropriate diagnostic modalities [7]. Pharmacologic treatment is the first-line therapy for pain management as a conservative measure when surgery fails to provide significant improvement [8]. Treatment include antiepileptics, nonsteroidal antiinflammatory drugs, oral steroids, antidepressants, and opioids. Antiepileptics, such as pregabalin (PGB), are widely used to treat the neuropathic component of pain in FBSS and may play a role in preventing pain after surgery $[9,10]$. Chronic opioid use is associated with a multitude of side effects, including immunosuppression, androgen deficiency, constipation, and depression [8]. Tapentadol (TPD), a new centrally acting analgesic with two mechanisms of action $(\mu$ opioid receptor agonism and noradrenaline reuptake inhibition), showed efficacy similar to classical opioids with better tolerability [11].

An important development in pain management has been the discovery that initiation and maintenance of neuropathic pain involve communication between neurons and nonneuronal immunocompetent cells, such as mast cells and microglia, together with a cascade of pro- and antiinflammatory cytokines [12-14]. Mast cells are often found close to nociceptive nerve terminals when activated after nerve injury and release mediators that cause peripheral sensitization and enhanced responsiveness of central nervous system neurons [15]. The persistent and aberrant excitability of primary sensory ganglia might also activate spinal microglia and thereby propagate neuroinflammation, prolonging the inflammatory state and leading to a condition of chronic pain [16].

An innovative approach in the management of chronic pain is represented by palmitoylethanolamide (PEA), a member of the $\mathrm{N}$-acylethanolamine family of fatty acid amide signaling molecules. PEA has an established history of antiallodynic and antihyperalgesic effects, which are mediated by downmodulation of proinflammatory mediator release from mast cells $[17,18]$ and reducing mast cell [19] and microglial cell activation $[19,20]$. At the molecular level, PEA is a peroxisome proliferator-activated receptor alpha (PPAR- $\alpha$ ) ligand that exerts anti-inflammatory, analgesic, and neuroprotective actions [21, 22]. Further, in a chronic constriction injury model of peripheral neuropathy, PEA's ability to rescue the peripheral nerve from inflammation and structural derangement was lost in PPAR- $\alpha$ null mice [23]. Several clinical studies have reported the use of ultramicronized PEA (umPEA) in the treatment of various syndromes associated with chronic pain that are poorly responsive to standard therapies [24-26]. The ultramicronization process is often used in the preparation of pharmaceuticals, as it yields a crystalline structure with higher energy content and smaller particle size which contributes to better distribution and diffusion and therefore a greater pharmacological efficacy [27, 28]. Interestingly, a recent study reported that micronized PEA/um-PEA displayed better oral efficacy compared to nonmicronized PEA in a rat model of inflammatory pain [29]. Based on these observations, the present study was designed to evaluate the efficacy of um-PEA (Normast) add-on therapy in conjunction with TPD + PGB standard treatment in the management of chronic pain in pain-resistant patients suffering from FBSS.

\section{Materials and Methods}

This observational study was carried out at the Out-Patient Center of Rheumatology and Pain Therapy (Santa Maria General Hospital of Terni, Italy), affiliated to the University of Perugia Medical School. Patients selected for the study were suffering from FBSS caused by laminectomy, discectomy, or vertebral stabilization, who came to our attention complaining of an increase in pain intensity compared to the immediate postoperative condition. See Table 1 for patient demographics. Pain treatment and pain intensity evaluation on the Visual Analogue Scale (VAS) (before and immediately after surgery) were collected for all patients from their clinical charts. The VAS is a continuous scale comprised of a horizontal line, 10 centimeters $(100 \mathrm{~mm})$ in length, anchored by 


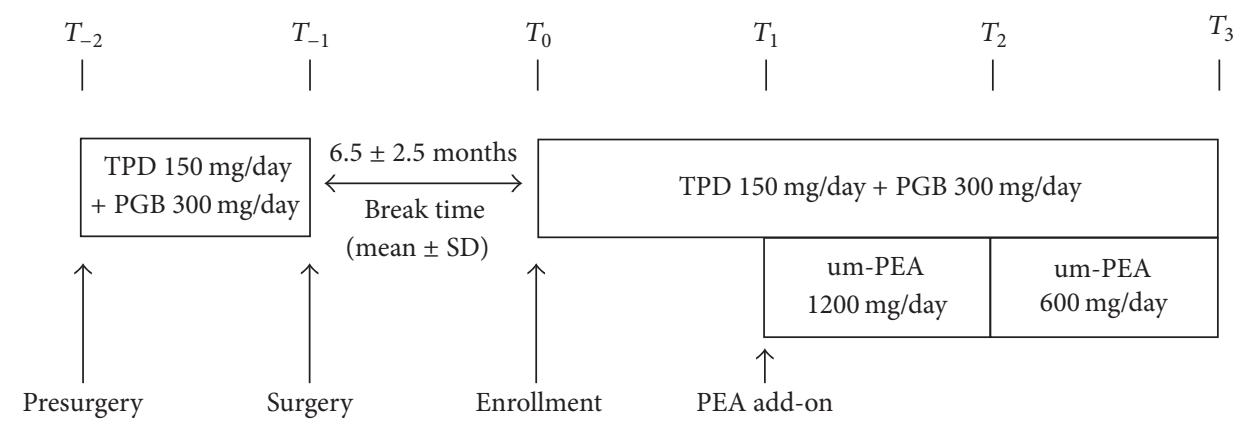

FIGURE 1: Study and treatment flow chart. The interval between each scheduled follow-up is one month. Break time is the mean time that passed after surgery, when patients return to the Out-Patient Center of Rheumatology and Pain Therapy complaining of persistent and increased pain. TPD: tapentadol; PGB: pregabalin; um-PEA: ultramicronized palmitoylethanolamide; SD: standard deviation.

TABLE 2: Pain intensity by VAS measurement.

\begin{tabular}{lcccccc}
\hline & $T_{-2}$ & $T_{-1}$ & $T_{0}$ & $T_{1}$ & $T_{2}$ & $T_{3}$ \\
\hline VAS (mean \pm SE) & $6.9 \pm 0.14$ & $5.1 \pm 0.13$ & $5.7 \pm 0.12$ & $4.3 \pm 0.11$ & $2.7 \pm 0.09$ & $1.7 \pm 0.11$ \\
\hline
\end{tabular}

VAS: Visual Analogue Scale; SE: standard error.

TABLE 3: Statistical analysis.

\begin{tabular}{|c|c|c|c|c|}
\hline & & Estimated difference & $\mathrm{SE}$ & $p$ value \\
\hline Presurgery $\left(T_{-2}\right)$ & Surgery $\left(T_{-1}\right)$ & 1.833 & 0.166 & $<0.0001$ \\
\hline Surgery $\left(T_{-1}\right)$ & Enrollment $\left(T_{0}\right)$ & -0.683 & 0.170 & 0.005 \\
\hline Enrollment $\left(T_{0}\right)$ & $T_{1}$ & 1.483 & 0.144 & $<0.0001$ \\
\hline$T_{1}$ & $T_{2}$ & 1.625 & 0.149 & $<0.0001$ \\
\hline$T_{2}$ & $T_{3}$ & 0.975 & 0.129 & $<0.0001$ \\
\hline
\end{tabular}

2 verbal descriptors, one for each symptom ( $0=$ no pain; $10=$ the worst pain imaginable) [30]. Patients were treated with TPD and PGB at variable doses, for three months in this study. One month after the start of standard treatment, um-PEA (Normast, Epitech Group SpA, Saccolongo, Italia) was added at $1200 \mathrm{mg} /$ day (two $600 \mathrm{mg}$ tablets daily) for one month followed by $600 \mathrm{mg} /$ day for the next month. Patients selected for this study were already under treatment with $\mathrm{TPD}+\mathrm{PGB}$ in the month before surgery, with a mean dosage of $150 \mathrm{mg}$ and $300 \mathrm{mg}$, respectively; the same dosages depending on the need of the patient were used in the prospective study. VAS evaluation was carried out every month for all patients at the time of enrollment $\left(T_{0}\right)$ and after one $\left(T_{1}\right)$, two $\left(T_{2}\right)$, and three $\left(T_{3}\right)$ months (Figure 1$)$. This study was carried out in accordance with the Helsinki Declaration of 1964 and its subsequent revisions and Good Clinical Practice. All patients provided informed written consent to participate. Statistical analysis was carried out to evaluate mean differences along time. Gender, time, and time-gender interaction were used as covariates. Single comparisons were evaluated using the Tukey-Kramer adjusted test.

\section{Results}

Thirty-five patients were enrolled in this study, all having undergone a previous surgical procedure (demographic details are summarized in Table 1). All subjects received, in the month before surgery, a standard treatment comprising $\mathrm{TPD}+\mathrm{PGB}$, at the mean daily dose of $150 \mathrm{mg}$ and $300 \mathrm{mg}$, respectively (individual patient dosing was determined by the physician, based on need). The mean intensity of pain evaluated by VAS one month before surgery $\left(T_{-2}\right)$ was $6.9 \pm$ 0.14 and decreased significantly immediately after surgery $\left(T_{-1}\right)$ to $5.1 \pm 0.13(p<0.0001)$. Subjects came to our attention after a median time of $6.5 \pm 2.5$ months (range: $2-8$ months) after surgery and presented a considerable increase in the mean pain intensity at the time of enrollment, with a mean VAS score of $5.7 \pm 0.12(p=0.0054)$ (Tables 2 and 3). All patients were treated for three months with standard medications (TPD + PGB) at mean daily doses of $150 \mathrm{mg}$ and $300 \mathrm{mg}$, respectively. One month after the start of standard treatment, um-PEA (Normast) was added for two months: $1200 \mathrm{mg} /$ day for the first month and $600 \mathrm{mg} /$ day for the second month. During the first month with TDP + PGB treatment only, the VAS score decreased from $5.7 \pm 0.12$ at the time of enrollment $\left(T_{0}\right)$ to $4.3 \pm 0.11\left(T_{1}\right)$; in the time periods following addition of um-PEA, VAS scores showed further decreases to $2.7 \pm 0.09\left(T_{2}\right)$ and $1.7 \pm 0.11\left(T_{3}\right.$, end of treatment) (Table 2, Figure 2). At each evaluation time, VAS was significantly reduced compared to the previous follow-up time $(p<0.0001)$ (Table 3$)$. 


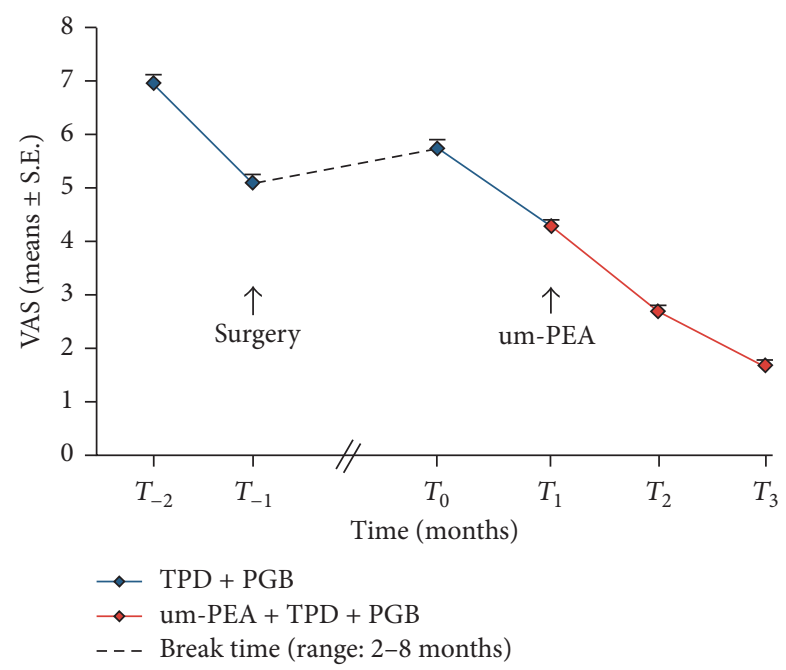

FIGURE 2: Changes in pain intensity by VAS measurement. FBSS patients selected at baseline $\left(T_{0}\right)$ received standard treatment comprising TPD + PGB for one month before surgery and showed a significant reduction immediately after surgery $(p<0.0001)$. There was a significant increase in pain intensity after a mean time of $6.5 \pm$ 2.5 months (range: $2-8$ months) following surgery $(p=0.0054)$. At this time $\left(T_{0}\right)$, patients were again given TPD + PGB for 3 months (up to $T_{3}$ ); um-PEA was added for the last two months $\left(T_{1}\right.$ to $\left.T_{3}\right)$. VAS reduction was statistically significant at each time $(p<0.0001)$.

\section{Discussion}

The present observational study provides preliminary evidence suggesting that um-PEA (Normast) as add-on treatment to conventional pharmacological regimens in patients suffering from FBSS contributes to a significant pain intensity reduction. As the complex physiopathology of this pain syndrome often renders monotherapy inadequate to achieve meaningful pain relief, polytherapy may thus represent a more fruitful therapeutic approach. TPD, a dual $\mu$-opioid receptor agonist and noradrenaline reuptake inhibitor, is efficacious in patients with nociceptive and neuropathic low back pain, either alone $[31,32]$ or in combination with the anticonvulsant PGB, the latter acting as an agonist of highvoltage-activated calcium channels [33,34]. The combination of TPD and PGB has a synergic effect in a rat model of neuropathic pain [35]. In the present study, TPD + PGB was administered as standard treatment to patients suffering from FBSS one month preceding surgery and after surgery (after a median time of $6.5 \pm 2.5$ months), when the patient first came to our clinic with complaints of persistent pain and pain of increased intensity. Although this conventional therapy significantly reduced VAS score, it failed to provide meaningful pain relief. Notably, pain reduction obtained in the first month after enrollment $\left(T_{1}-T_{0}\right)$ of $1.48 \pm 0.14$ was comparable to that achieved in the month leading up to surgery $\left(T_{-2}-T_{-1}\right)$ $(1.83 \pm 0.17)$, even though the latter period encompassed the surgery variable. While encouraging, the VAS score at $T_{1}$ exceeded 4 , an indication still of moderate pain intensity. In the search for new molecules as add-on therapy in the treatment of FBSS, we decided to assess the potential of
um-PEA. PEA is an endogenous fatty acid amide signaling molecule produced on demand in response to cellular stress or injury. The anti-inflammatory and analgesic effects of PEA are likely accounted for by several not mutually exclusive mechanisms. PEA acts by downregulating mast cell degranulation via an "autacoid local inflammation antagonism" (ALIA) effect [36]. A "receptor mechanism" has also been proposed, based on the capability of PEA to directly stimulate either an as-yet uncharacterized cannabinoid CB2 receptorlike target $[37,38]$ or the nuclear peroxisome proliferatoractivated receptor- $\alpha$, the latter mediating many of PEA's anti-inflammatory effects [22]. In vivo studies show PEA to possess anti-inflammatory and pain-relieving properties $[23,37,39]$. Moreover, a number of clinical studies point to the potential therapeutic utility of this fatty acid amide in different neuropathic pain syndromes [24, 40-42]. The combination of PEA in association with other molecules results in pain reduction in neuropathic pain patients, with good safety and tolerability. At present, very little information is available concerning the use of PEA in FBSS. Gatti et al. [24] evaluated um-PEA's effects on chronic pain associated with different pathological conditions, including a group of 76 patients afflicted with FBSS. In their study, um-PEA's effect on reduction of pain intensity was evident for FBSS patients, as well as for the other groups of patients analyzed separately.

After the first month of TPD + PGB treatment, FBSS patients had a pain reduction of $1.48 \pm 0.14\left(T_{1}-T_{0}\right)$. In the subsequent two months with um-PEA as add-on therapy, there was a further and significant decrease in pain intensity of $1.62 \pm 0.15\left(T_{2}-T_{1}\right)$ after the second month and $0.97 \pm 0.13$ $\left(T_{3}-T_{2}\right)$ after the third month (Tables 2 and 3, Figure 2). To assess whether or not the increased effectiveness of therapy in the second month was attributable to um-PEA, we compared our results with those from an arm of a recent double-blind study where patients affected by chronic low back pain were treated with a combination of TPD $(300 \mathrm{mg})+$ PGB $(300 \mathrm{mg})$ for 2 months (after a titration period). Pain intensity assessed as VAS score decreased from $5.9 \pm 0.10$ (the reported VAS \pm SE was calculated, following the system suggested in Figure 3 of Baron et al., 2015 [33]) at baseline (randomization time) to $4.4 \pm 0.151$ after one month of treatment and to $4.2 \pm 0.201$ after the second month, suggesting a decrease in TPD + PGB effect over time in this patient group [33]. One might well compare the two trends over time, as the starting VAS scores were similar both in our study and in that of Baron et al. [33] (5.7 and 5.9, resp.). In their comparative study, Baron et al. [33] observed decreased effectiveness of TPD + PGB therapy over time especially after the second month, with stabilization of the VAS score which did not decrease under a moderate score equal to 4 . In contrast, our study demonstrated in the second month a clear increase in effectiveness of treatment, which led to a further and significant reduction in pain intensity that we ascribe to um-PEA add-on. The increased effectiveness of TPD + PGB treatment in the second month is unlikely to have occurred spontaneously, taking into account also the pain intensity trend curve of TPD + PGB combination only. Importantly, none of the patients experienced adverse events after um-PEA add-on to the standard treatment. The openlabel design of this study, together with the limited number 
of patients, does not allow one to judge the extent to which um-PEA further improved the painful symptoms compared to standard treatment only. Furthermore, the relatively short treatment period (two months) does not allow one to predict effectiveness over the longer term. These caveats notwithstanding, our study is an example of how one may achieve an overall improvement in conventional drug treatment without side effects. The use of um-PEA (Normast) as add-on therapy might result in more efficacious pain relief through an action on immune cells, especially in cases refractory to standard therapies which act on neurons. Future studies should evaluate the benefits of combining these treatments on larger populations in controlled trials with more refined inclusion/exclusion criteria and conditions.

\section{Ethical Approval}

All procedures were carried out in accordance with the ethical standards for responsible conduct on human experimentation (institutional and national) and with the Helsinki Declaration of 1964, as revised in 2013. The study was approved by the Local Ethical Committee of Umbria Region (Italy).

\section{Disclosure}

All named authors meet the International Committee of Medical Journal Editors (ICMJE) criteria for authorship, take responsibility for the integrity of the work as a whole, and have read and approved the final version being submitted for publication.

\section{Conflicts of Interest}

The authors have no conflicts of interest to declare.

\section{Acknowledgments}

This study was carried out under the patronage of the Italian Association for the Study of Pain (AISD), the Paolo Procacci Foundation (PPF), and the European League Against Pain (EULAP). The authors wish to thank Dr. Carlo Schievano for the statistical analysis and Ms. Marta di Felice for excellent secretarial work.

\section{References}

[1] D. M. Long, "Failed back surgery syndrome," Neurosurgery Clinics of North America, vol. 2, no. 4, pp. 899-919, 1991.

[2] C.-W. Chan and P. Peng, "Failed back surgery syndrome," Pain Medicine, vol. 12, no. 4, pp. 577-606, 2011.

[3] E. W. Fritsch, J. Heisel, and S. Rupp, "The failed back surgery syndrome: reasons, intraoperative findings, and long-term results: a report of 182 operative treatments," Spine, vol. 21, no. 5, pp. 626-633, 1996.

[4] J. D. Markman, B. T. Kress, M. Frazer, R. Hanson, V. Kogan, and J. H. Huang, "Screening for neuropathic characteristics in failed back surgery syndromes: challenges for guiding treatment," Pain Medicine (United States), vol. 16, no. 3, pp. 520-530, 2015.
[5] R. D. Guyer, M. Patterson, and D. D. Ohnmeiss, "Failed back surgery syndrome: Diagnostic evaluation," Journal of the American Academy of Orthopaedic Surgeons, vol. 14, no. 9, pp. 534543, 2006.

[6] L. M. McCracken and D. C. Turk, "Behavioral and cognitivebehavioral treatment for chronic pain: outcome, predictors of outcome, and treatment process," Spine, vol. 27, no. 22, pp. 2564-2573, 2002.

[7] A. Hussain and M. Erdek, "Interventional pain management for failed back surgery syndrome," Pain Practice, vol. 14, no. 1, pp. 64-78, 2014.

[8] Z. Baber and M. A. Erdek, "Failed back surgery syndrome: Current perspectives," Journal of Pain Research, vol. 9, pp. 979987, 2016.

[9] M. B. Khosravi, S. Azemati, and M. A. Sahmeddini, "Gabapentin versus naproxen in the management of failed back surgery syndrome; a randomized controlled trial," Acta Anaesthesiologica Belgica, vol. 65, no. 1, pp. 31-37, 2014.

[10] A. Canos, L. Cort, Y. Fernández et al., "Preventive analgesia with pregabalin in neuropathic pain from "failed back surgery syndrome": assessment of sleep quality and disability," Pain Medicine (United States), vol. 17, no. 2, pp. 344-352, 2016.

[11] G. Varrassi, F. Marinangeli, A. Piroli, S. Coaccioli, and A. Paladini, "Strong analgesics: Working towards an optimal balance between efficacy and side effects," European Journal of Pain, vol. 14, no. 4, pp. 340-342, 2010.

[12] K. Ren and R. Dubner, "Interactions between the immune and nervous systems in pain," Nature Medicine, vol. 16, no. 11, pp. 1267-1276, 2010.

[13] M. Calvo, J. M. Dawes, and D. L. Bennett, "The role of the immune system in the generation of neuropathic pain," The Lancet Neurology, vol. 11, no. 7, pp. 629-642, 2012.

[14] P. Sacerdote, S. Franchi, S. Moretti et al., "Cytokine modulation is necessary for efficacious treatment of experimental neuropathic pain," Journal of Neuroimmune Pharmacology, vol. 8, no. 1, pp. 202-211, 2013.

[15] H. MacHelska, "Dual peripheral actions of immune cells in neuropathic pain," Archivum Immunologiae et Therapiae Experimentalis, vol. 59, no. 1, pp. 11-24, 2011.

[16] I. Kazuhide and T. Makoto, "Microglia and neuropathic pain," Glia, vol. 57, no. 14, pp. 1469-1479, 2009.

[17] M. Granberg, C. J. Fowler, and S. O. P. Jacobsson, "Effects of the cannabimimetic fatty acid derivatives 2-arachidonoylglycerol, anandamide, palmitoylethanolamide and methanandamide upon IgE-dependent antigen-induced $\beta$-hexosaminidase, serotonin and TNF $\alpha$ release from rat RBL-2H3 basophilic leukaemia cells," Naunyn-Schmiedeberg's Archives of Pharmacology, vol. 364, no. 1, pp. 66-73, 2001.

[18] M. Fusco, S. D. Skaper, S. Coaccioli, G. Varrassi, and A. Paladini, "Degenerative joint diseases and neuroinflammation," Pain Practice, vol. 17, no. 4, pp. 522-532, 2017.

[19] I. Bettoni, F. Comelli, A. Colombo, P. Bonfanti, and B. Costa, "Non-neuronal cell modulation relieves neuropathic pain: efficacy of the endogenous lipid palmitoylethanolamide," CNS and Neurological Disorders: Drug Targets, vol. 12, no. 1, pp. 34-44, 2013.

[20] G. Varrassi, M. Fusco, S. Coaccioli, and A. Paladini, "Chronic pain and neurodegenerative processes in elderly people," Pain Practice, vol. 15, no. 1, pp. 1-3, 2015.

[21] M. Alhouayek and G. G. Muccioli, "Harnessing the antiinflammatory potential of palmitoylethanolamide," Drug Discovery Today, vol. 19, no. 10, pp. 1632-1639, 2014. 
[22] J. Lo Verme, J. Fu, G. Astarita et al., "The nuclear receptor peroxisome proliferator-activated receptor- $\alpha$ mediates the antiinflammatory actions of palmitoylethanolamide," Molecular Pharmacology, vol. 67, no. 1, pp. 15-19, 2005.

[23] L. Di Cesare Mannelli, G. D’Agostino, A. Pacini et al., "Palmitoylethanolamide is a disease-modifying agent in peripheral neuropathy: pain relief and neuroprotection share a PPARalpha-mediated mechanism," Mediators of Inflammation, vol. 2013, Article ID 328797, 12 pages, 2013.

[24] A. Gatti, M. Lazzari, V. Gianfelice, A. Di Paolo, E. Sabato, and A. F. Sabato, "Palmitoylethanolamide in the Treatment of Chronic Pain Caused by Different Etiopathogenesis," Pain Medicine (United States), vol. 13, no. 9, pp. 1121-1130, 2012.

[25] P. Desio, "Aliamides and duloxetina in the treatment of low back pain," Pathos, vol. 23, no. 1, 2016.

[26] R. Del Giorno, S. Skaper, A. Paladini, G. Varrassi, and S. Coaccioli, "Palmitoylethanolamide in fibromyalgia: results from prospective and retrospective observational studies," Pain and Therapy, vol. 4, no. 2, pp. 169-178, 2015.

[27] S. Rao, Y. Song, F. Peddie, and A. M. Evans, "Particle size reduction to the nanometer range: a promising approach to improve buccal absorption of poorly water-soluble drugs," International journal of nanomedicine, vol. 6, pp. 1245-1251, 2011.

[28] S. Sareen, G. Mathew, and L. Joseph, "Improvement in solubility of poor water-soluble drugs by solid dispersion," International Journal of Pharmaceutical Investigation, vol. 2, no. 1, pp. 12-17, 2012.

[29] D. Impellizzeri, G. Bruschetta, M. Cordaro et al., "Micronized/ ultramicronized palmitoylethanolamide displays superior oral efficacy compared to nonmicronized palmitoylethanolamide in a rat model of inflammatory pain," Journal of Neuroinflammation, vol. 11, no. 1, article 136, 2014.

[30] G. A. Hawker, S. Mian, T. Kendzerska, and M. French, "Measures of adult pain: Visual Analog Scale for Pain (VAS Pain), Numeric Rating Scale for Pain (NRS Pain), McGill Pain Questionnaire (MPQ), Short-Form McGill Pain Questionnaire (SF-MPQ), Chronic Pain Grade Scale (CPGS), Short Form-36 Bodily Pain Scale (SF-36 BPS), and measure of Intermittent and Constant Osteoarthritis Pain (ICOAP)," Arthritis Care \& Research, vol. 63, supplement 11, pp. S240-S252, 2011.

[31] I. Steigerwald, M. Müller, A. Davies et al., "Effectiveness and safety of tapentadol prolonged release for severe, chronic low back pain with or without a neuropathic pain component: Results of an open-label, phase 3b study," Current Medical Research and Opinion, vol. 28, no. 6, pp. 911-936, 2012.

[32] R. Gálvez, M. Schäfer, G. Hans, D. Falke, and I. Steigerwald, "Tapentadol prolonged release versus strong opioids for severe, chronic low back pain: Results of an open-label, phase 3b study," Advances in Therapy, vol. 30, no. 3, pp. 229-259, 2013.

[33] R. Baron, E. Martin-Mola, M. Müller, C. Dubois, D. Falke, and I. Steigerwald, "Effectiveness and Safety of Tapentadol Prolonged Release (PR) Versus a Combination of Tapentadol PR and Pregabalin for the Management of Severe, Chronic Low Back Pain With a Neuropathic Component: A Randomized, Doubleblind, Phase 3b Study," Pain Practice, vol. 15, no. 5, pp. 455-470, 2015.

[34] R. Baron, A. Binder, N. Attal, R. Casale, A. H. Dickenson, and R.-D. Treede, "Neuropathic low back pain in clinical practice," European Journal of Pain (United Kingdom), vol. 20, no. 6, pp. 861-873, 2016.

[35] T. Christoph, J. De Vry, K. Schiene, R. J. Tallarida, and T. M. Tzschentke, "Synergistic antihypersensitive effects of pregabalin and tapentadol in a rat model of neuropathic pain," European Journal of Pharmacology, vol. 666, no. 1-3, pp. 72-79, 2011.

[36] L. Aloe, A. Leon, and R. Levi-Montalcini, "A proposed autacoid mechanism controlling mastocyte behaviour," Agents and Actions, vol. 39, 1, pp. C145-C147, 1993.

[37] B. Costa, F. Comelli, I. Bettoni, M. Colleoni, and G. Giagnoni, "The endogenous fatty acid amide, palmitoylethanolamide, has anti-allodynic and anti-hyperalgesic effects in a murine model of neuropathic pain: involvement of CB1, TRPV1 and PPAR $\gamma$ receptors and neurotrophic factors," Pain, vol. 139, no. 3, pp. 541$550,2008$.

[38] A. Calignano, G. La Rana, A. Giuffrida, and D. Piomelli, “Control of pain initiation by endogenous cannabinoids," Nature, vol. 394, no. 6690, pp. 277-281, 1998.

[39] Z. Helyes, J. Németh, M. Thán, K. Bölcskei, E. Pintér, and J. Szolcsányi, "Inhibitory effect of anandamide on resiniferatoxininduced sensory neuropeptide release in vivo and neuropathic hyperalgesia in the rat," Life Sciences, vol. 73, no. 18, pp. 23452353, 2003.

[40] G. Guida, M. De Martino, A. De Fabiani, L. Canteri, A. Alexandre, G. Vassallo et al., "La Palmitoiletanolamide (Normast ${ }^{\circledR}$ ) en el dolor neuropático crónico por lumbociatalgia de tipo compresivo:estudio clinico multícéntrico," Dolor, vol. 25, 35, no. 1, p. 42, 2010.

[41] A. Truini, A. Biasiotta, G. Di Stefano et al., "Palmitoylethanolamide restores myelinated-fibre function in patients with chemotherapy-induced painful neuropathy," CNS \& Neurological Disorders-Drug Targets, vol. 10, no. 8, pp. 916-920, 2011.

[42] A. Paladini, M. Fusco, T. Cenacchi, C. Schievano, A. Piroli, and G. Varrassi, "Palmitoylethanolamide, a special food for medical purposes, in the treatment of chronic pain: A pooled data metaanalysis," Pain Physician, vol. 19, no. 2, pp. 11-24, 2016. 


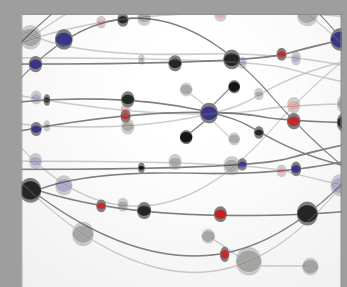

The Scientific World Journal
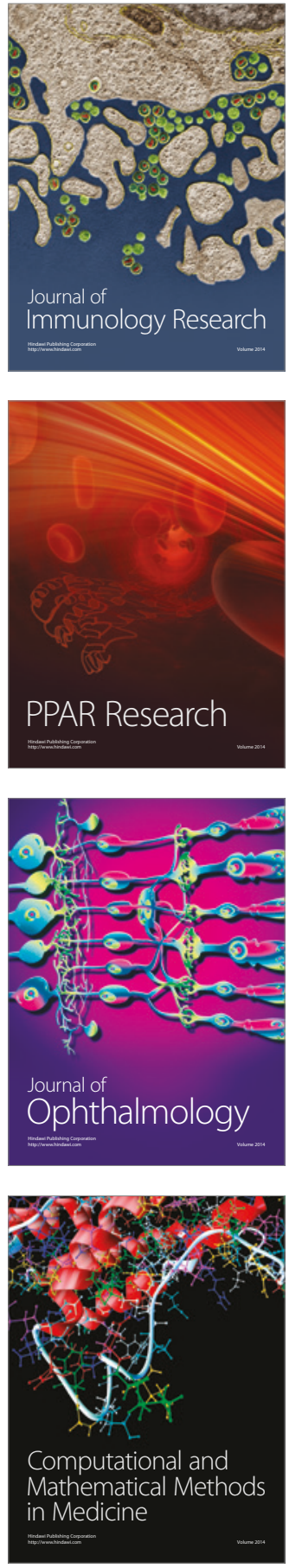

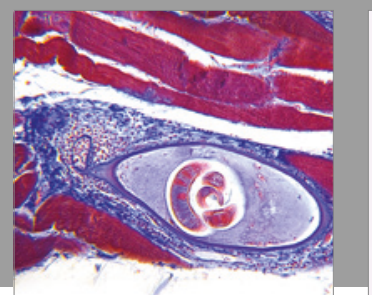

Gastroenterology Research and Practice
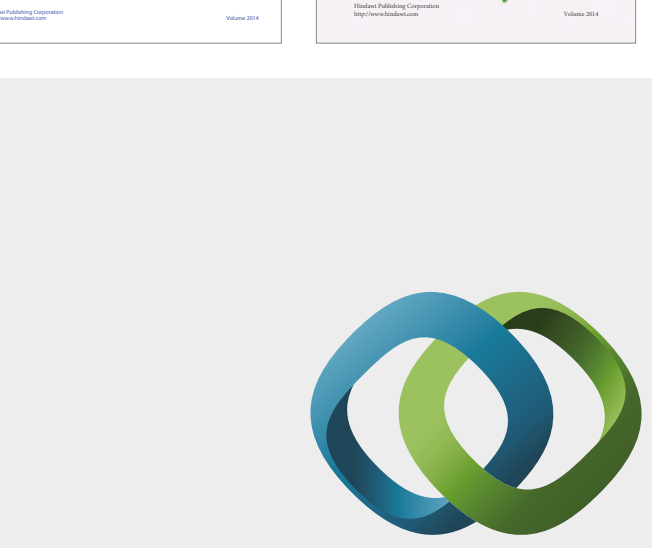

\section{Hindawi}

Submit your manuscripts at

https://www.hindawi.com
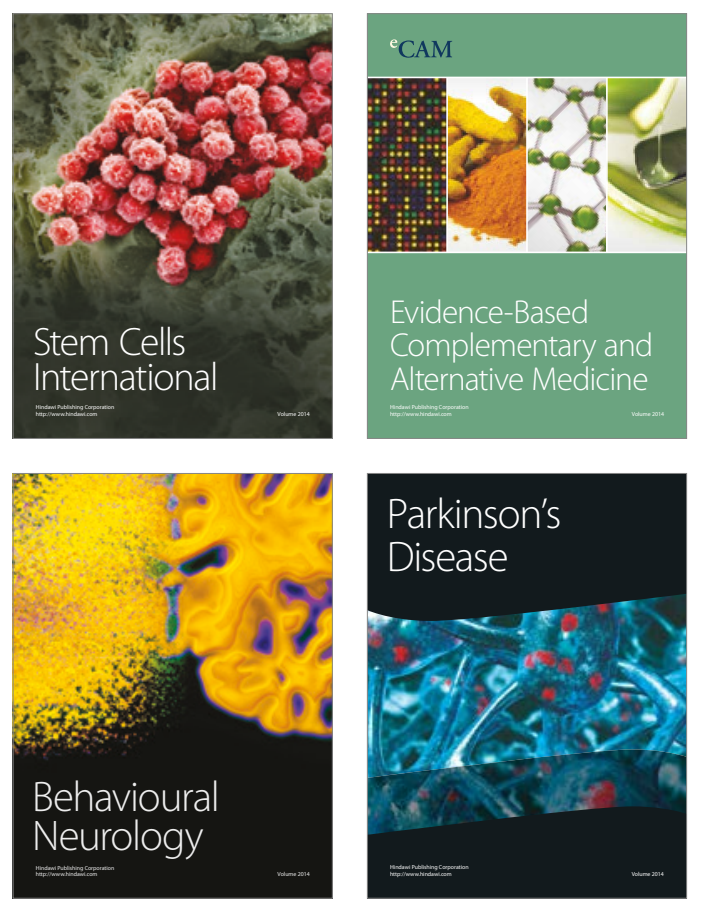
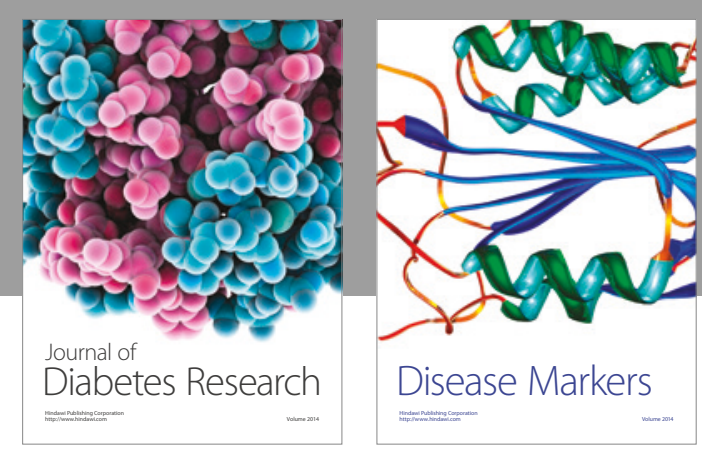

Disease Markers
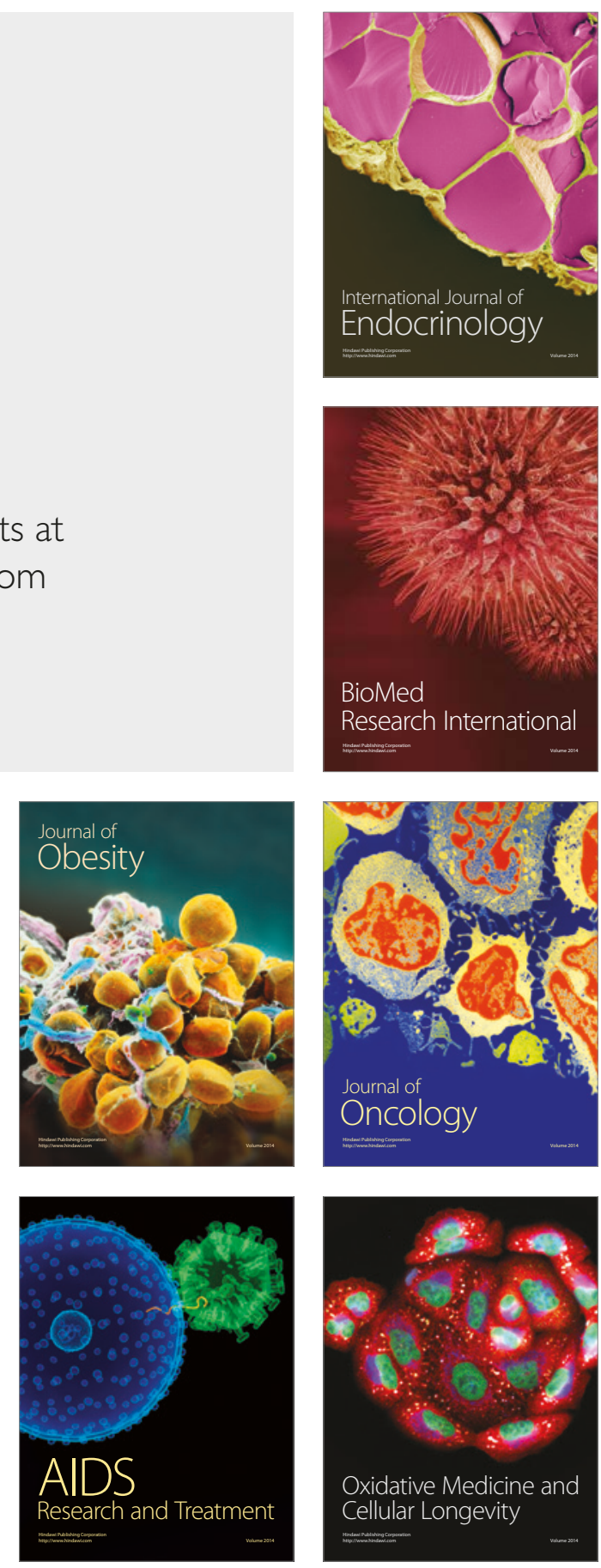